\title{
Challenges to Addressing Patient-Perpetrated Sexual Harassment in Veterans Affairs Healthcare Settings
}

\author{
Karissa M. Fenwick, PhD, MSW, LCSW' (1), Tana M. Luger, PhD, MPH ${ }^{1,2}$, \\ Karen E. Dyer, PhD, MPH', Joya G. Chrystal, MSW, LCSW', \\ Alison B. Hamilton, $\mathrm{PhD}, \mathrm{MPH}^{1,3}$, Elizabeth M. Yano, PhD, MSPH ${ }^{1,4,5}$, and Ruth Klap, $P h D^{1,3}$
}

\begin{abstract}
'Center for the Study of Healthcare Innovation, Implementation and Policy (CSHIIP), VA Greater Los Angeles Healthcare System, Health Services Research and Development (HSR\&D), Los Angeles, CA, USA; ${ }^{2}$ Covenant Health Network, Phoenix, AZ, USA; ${ }^{3}$ Department of Psychiatry and Biobehavioral Sciences, UCLA David Geffen School of Medicine, Jane \& Terry Semel Institute for Neuroscience \& Human Behavior, Los Angeles, CA, USA; ${ }^{4}$ Department of Health Policy and Management, UCLA Fielding School of Public Health, Los Angeles, CA, USA; ${ }^{5}$ Department of Medicine, UCLA David Geffen School of Medicine, 885 Tiverton Drive, Los Angeles, CA, USA.
\end{abstract}

\begin{abstract}
BACKGROUND: Patient-perpetrated sexual harassment adversely affects healthcare organizations, staff, and other patients, yet few institutions have clear policies to address it. Understanding the challenges to addressing patient-perpetrated harassment can inform development of institutional guidelines and interventions.
\end{abstract}

OBJECTIVE: To identify challenges and stakeholderdriven recommendations for addressing patientperpetrated sexual harassment of women staff and patients at Veterans Health Administration (VA) facilities.

DESIGN: We conducted qualitative interviews with 24 staff, clinicians, and administrators across four VA healthcare facilities.

PARTICIPANTS: We used snowball sampling to identify stakeholders with expertise in overseeing care environments, providing care to women patients, and/or managing disruptive patient behavior.

APPROACH: We interviewed participants in-person or via phone using a semi-structured guide. Two members of the research team analyzed the interview data using the constant comparative method.

KEY RESULTS: Participants identified challenges to addressing patient-perpetrated harassment of women staff and patients that were interrelated and spanned multiple levels. Perceived organizational-level challenges included a climate of tolerance for harassment, lack of formal policies, and insufficient leadership support. At the staff level, perceived challenges included ambiguity around defining harassment, fear of negatively impacting patient-staff dynamics, and competing priorities. Finally, participants identified patient-level challenges, including patient characteristics such as age, cognitive impairment, and psychiatric diagnoses that complicated assessments of intentionality and culpability. Participant recommendations focused on development and implementation of policies, reporting systems, public norms campaigns, staff and patient education, and bystander intervention training.

Prior Presentations We presented a version of this manuscript's findings at the 2020 American Public Health Association Annual Meeting.

Received July 14, 2020

Accepted December 3, 2020

Published online October 25, 2021
CONCLUSIONS: VA offers unique opportunities for studying patient-perpetrated harassment of women staff and patients due to its majority-male patient population, culture informed by military gender norms, and commitment to reducing harassment at its facilities. Our findings highlight the complexity of addressing patient-perpetrated harassment and underscore the need for systemic, multilevel interventions.

KEY WORDS: sexual harassment; gender; Veterans; organizational climate.

$\mathrm{J}$ Gen Intern Med 36(8):2332-8

DOI: $10.1007 / \mathrm{s} 11606-020-06390-0$

(c) This is a U.S. government work and not under copyright protection in the U.S.; foreign copyright protection may apply 2021

\section{BACKGROUND}

Sexual harassment includes unwanted physical (e.g., inappropriate touching), verbal (e.g., sexual or derogatory remarks), and non-verbal (e.g., stares, whistles) interactions. ${ }^{1}$ Gender harassment, the most common subtype of sexual harassment, involves behaviors conveying hostile or degrading attitudes towards members of a particular gender. ${ }^{1}$ A recent study found that over $60 \%$ of women physicians experienced sexual or gender harassment by patients in the past year, ${ }^{2}$ and other research shows high prevalence of patient-perpetrated harassment of medical trainees, nurses, and allied health clinicians. ${ }^{3-7}$ Patient-perpetrated harassment contributes to elevated rates of sexual harassment reported by women in medicine compared to those in other professions and adversely impacts productivity, advancement, retention, mental health, and sense of safety at work. ${ }^{2,8-10}$

In addition to harassing staff, patients may direct sexual harassment toward other patients in waiting rooms or common areas. Some research suggests that these unwanted interactions, termed public harassment, are rare in healthcare settings. ${ }^{11}$ However, $25 \%$ of women Veteran primary care users report being harassed by men Veterans on Veterans Health Administration (VA) grounds, highlighting a need for further study across varied contexts. ${ }^{12}$ Public harassment is associated with 
negative physical, psychological, and social outcomes including depression, anxiety, sleep disturbances, decreased sense of safety, and restricted freedom of movement. ${ }^{11,13,14}$ When occurring in healthcare settings, it may result in missed or delayed care. ${ }^{12}$

Increased awareness of the prevalence and impact of sexual harassment of women providers in healthcare settings has led to calls for institutions to intervene. ${ }^{15-18}$ However, most of this attention has focused on harassment perpetrated by staff. Patient-perpetrated harassment creates unique challenges, and even top US academic medical institutions lack clear policies and protocols to address it. ${ }^{19,}{ }^{20}$ Furthermore, recent studies indicate that both men and women providers desire more training in managing patient-perpetrated harassment. ${ }^{21,}{ }^{22} \mathrm{An}$ understanding of the barriers and challenges to addressing patient-perpetrated harassment may help guide recommendations for policies, guidelines, and training interventions.

Social science research shows that an organization's culture, climate, leadership, tolerance for sexual harassment, and gender norms contribute to harassment and may act as barriers to change efforts. ${ }^{23-26}$ These studies focus on harassment between colleagues, but it is likely that the organizational context also influences patient-perpetrated harassment. ${ }^{8}$ In addition to organizational factors, the primacy of the patientprovider relationship complicates efforts to address patientperpetrated harassment in healthcare settings. ${ }^{20}$ Initial evidence suggests that providers may view harassment from patients as simply "part of the job" or avoid intervening due to fears of retaliation, damaging the therapeutic relationship, or disrupting treatment. ${ }^{20,27,28}$ More research is needed to build upon this work and confirm which barriers are most salient to addressing patient-perpetrated harassment in healthcare settings.

VA healthcare facilities are particularly conducive to studying the challenges to addressing harassment of women by men patients. VA is embedded in military culture, which is hierarchical, traditionally masculine, and associated with high rates of sexual harassment and assault. ${ }^{29} \mathrm{In}$ addition, although numbers are growing, women comprise only $8 \%$ of VA patients, creating a male-majority context that may enable patient-perpetrated harassment. ${ }^{30,} 31$ Evidence that harassment is especially distressing for the approximately $38-53 \%$ of women Veterans with histories of military sexual trauma ${ }^{32,}{ }^{33}$ further underscores the urgency of addressing harassment at VA facilities. ${ }^{12,} 34$

Recognizing these issues, VA is committed to reducing sexual and gender harassment as part of its mission to improve quality of care for women Veterans. ${ }^{35}$ In 2015, VA Women's Health Services commissioned an assessment of public harassment of women by men patients at VA healthcare facilities. We conducted and analyzed interviews with VA stakeholders to (1) identify challenges to addressing patientperpetrated harassment of women staff and patients at VA sites of care; and (2) offer preliminary recommendations for interventions to address patient-perpetrated harassment in healthcare settings.

\section{METHODS}

\section{Participants}

Two members of the research team (RK, JC) conducted interviews with 24 participants in June-August 2016. We developed a list of key stakeholder roles and obtained contact information for individual stakeholders from VA Women's Health Practice Based Research Network (PBRN) site leads and other facility representatives. ${ }^{36}$ Given that we were interested in understanding harassment of both women staff and women patients, the list included stakeholders with practice/policy experience related to general (male-majority) patient care and those with experience specific to women's care. We used snowball sampling to identify additional participants and sent 31 interview requests across four PBRN facilities. Facilities were located in the Western, Midwestern, and Northeastern regions of the USA and included one rural and three urban sites.

\section{Interviews}

We developed the semi-structured interview guide based on literature review and previous work related to harassment at VA. ${ }^{12,}{ }^{30}$ We asked participants to (1) describe their experiences, observations, or knowledge of harassment by men patients toward women staff and/or women patients; (2) discuss VA's management of patientperpetrated harassment; and (3) provide feedback about potential future interventions for harassment at VA facilities. Interview questions included "What are the challenges to addressing harassment at VA?"; "Are you aware of any formal policies and procedures put in place to address harassment?"; and "How should VA handle harassment incidents on campus?" Interviews were sufficiently openended to allow participants to elaborate on topics they deemed important. At the end of the interview, we asked, "Is there anyone else we should speak with about harassment within VA?" We conducted approximately $20 \%$ of interviews in person, and the rest via telephone. Interviews averaged 30 minutes and were audio recorded. VA Women's Health Services provided a determination of nonresearch for this project, indicating that it was a quality improvement activity. Therefore, we did not require participants to sign consent forms but did obtain their consent for audio recording.

\section{Data Analysis}

We developed a codebook capturing both a priori topics derived from the interview guide and themes generated from the data. Two research team members (KF, TL) coded the deidentified interview transcripts in ATLAS.ti (v8) using the constant comparative method. ${ }^{37}$ We discussed coding discrepancies until consensus was reached and organized coded passages by topic to facilitate identification of larger themes. ${ }^{37,} 38$ 


\section{RESULTS}

Participants included facility directors $(n=5)$, Women Veterans Program Managers (plan, execute, and evaluate services for women Veterans; $n=4)$, Military Sexual Trauma Coordinators (promote access to care and implementation of policies related to military sexual trauma; $n=3)$, women's health directors $(n=2)$, police chiefs $(n=2)$, Disruptive Behavior Committee members (interdisciplinary committee focused on reducing patientgenerated disruptive behavior; $n=2$ ), and other providers (social worker, psychologist, attending physician; $n=3$ ) and administrators (facility-specific roles, collapsed to protect confidentiality; $n=3$ ). Mean participant tenure in their current position was approximately 4 years (range 4.5 months-13 years). Seventy-nine percent of the participants were women.

\section{Challenges to Addressing Harassment}

Participants identified challenges to addressing patientperpetrated harassment of women staff and patients stemming from organizational, staff, and patient factors. These are summarized in Table 1 and in the text below. To improve readability, some quotes are edited to remove utterances and redundant wording.

Organizational Factors. Participants described how VA culture acts as a barrier to addressing patient-perpetrated harassment of women staff and patients. This culture is driven by a climate of tolerance for sexual harassment, or shared perceptions that VA tolerates harassment by men patients and fails to hold perpetrators accountable. As one participant explained, "I feel like it's just tolerated and, once things are tolerated, it just becomes the culture and not even seen any more as a bad thing." (no. 13). Another

Table 1 Stakeholder-Identified Challenges and Recommendations for Addressing Patient-Perpetrated Harassment

\begin{tabular}{|c|c|c|c|}
\hline Challenge & Description & Example quote* & $\begin{array}{l}\text { Stakeholder } \\
\text { recommendations }\end{array}$ \\
\hline \multicolumn{4}{|l|}{ External } \\
\hline Societal culture & $\begin{array}{l}\text { Societal norms and values that enable } \\
\text { harassment }\end{array}$ & $\begin{array}{l}\text { "It is a societal concern and it is not just military, it's } \\
\text { not just Veterans Administration." (no. 05) }\end{array}$ & N/A \\
\hline Military culture & $\begin{array}{l}\text { Military norms and values that enable } \\
\text { harassment }\end{array}$ & $\begin{array}{l}\text { "I always think of the VA as like pseudo military, it's } \\
\text { like one level down from the military culture. And the } \\
\text { military culture, of course, is having a real problem } \\
\text { with [harassment]." (no. 16) }\end{array}$ & $\mathrm{N} / \mathrm{A}$ \\
\hline \multicolumn{4}{|l|}{ Organization } \\
\hline $\begin{array}{l}\text { Climate around } \\
\text { harassment }\end{array}$ & $\begin{array}{l}\text { Shared perceptions that VA tolerates } \\
\text { patient-perpetrated harassment and fails } \\
\text { to hold perpetrators accountable }\end{array}$ & $\begin{array}{l}\text { "There becomes kind of like this learned helplessness } \\
\text { for a lot of the employees...well this is just part of the } \\
\text { culture...get used to it because it's not going } \\
\text { anywhere." (no. 07) }\end{array}$ & $\begin{array}{l}\text { Norms campaigns } \\
\text { Patient education } \\
\text { Bystander intervention } \\
\text { Staff training } \\
\text { Policies/guidelines }\end{array}$ \\
\hline Policies/guidelines & $\begin{array}{l}\text { Lack of clear polices for addressing } \\
\text { patient-perpetrated harassment }\end{array}$ & $\begin{array}{l}\text { "There is not a really clear process or procedure in } \\
\text { reporting things like this." (no. 04) }\end{array}$ & Policies/guidelines \\
\hline Leadership & $\begin{array}{l}\text { Lack of leader awareness and/or support } \\
\text { around the need for interventions to } \\
\text { address harassment }\end{array}$ & $\begin{array}{l}\text { "I'm not sure how much upper management is aware } \\
\text { of it...it does not seem like there's been any action } \\
\text { taken on that." (no. 12) }\end{array}$ & Leadership support \\
\hline \multicolumn{4}{|l|}{ Staff } \\
\hline Cognitive appraisals & $\begin{array}{l}\text { Ambiguity around labeling harassment } \\
\text { and assessing whether/how to intervene }\end{array}$ & $\begin{array}{l}\text { "[Staff think], 'Oh... the [woman] Veteran did not even } \\
\text { say that [the harassment] made them uncomfortable, so } \\
\text { maybe we should not report that." (no. 04) }\end{array}$ & $\begin{array}{l}\text { Staff training } \\
\text { Policies/guidelines }\end{array}$ \\
\hline $\begin{array}{r}\text { Patient-staff } \\
\text { dynamics }\end{array}$ & $\begin{array}{l}\text { Fear of damaging the therapeutic } \\
\text { relationship or provoking patient } \\
\text { retaliation }\end{array}$ & $\begin{array}{l}\text { "If I were to have confronted that patient yesterday, } \\
\text { that would have made my entire interaction with him } \\
\text { more difficult." (no. 18) }\end{array}$ & Staff training \\
\hline Competing priorities & $\begin{array}{l}\text { Lack of time or staff resources to address } \\
\text { harassment given other priorities, needs, } \\
\text { or duties }\end{array}$ & $\begin{array}{l}\text { "Are you going to have the police officer taking the } \\
\text { [harassment] report, or are they going to be up on this } \\
\text { mental health unit dealing with an issue up there?" (no. } \\
\text { 09) }\end{array}$ & $\begin{array}{l}\text { Leadership support } \\
\text { Policies/guidelines }\end{array}$ \\
\hline \multicolumn{4}{|c|}{ ( } \\
\hline Awareness & $\begin{array}{l}\text { Lack of awareness about definition and } \\
\text { impact of harassment }\end{array}$ & $\begin{array}{l}\text { "I know some of the men [patients] may not really } \\
\text { even consider what they are doing harassment and they } \\
\text { might think it's just mild to call someone 'Honey' or } \\
\text { 'Baby' or whatever..." (no. 15) }\end{array}$ & $\begin{array}{l}\text { Norms campaigns } \\
\text { Patient education } \\
\text { Bystander intervention }\end{array}$ \\
\hline Clinical diagnoses & $\begin{array}{l}\text { Psychiatric or other clinical diagnoses } \\
\text { that complicate management of } \\
\text { harassing behaviors }\end{array}$ & $\begin{array}{l}\text { "The issue is that you have to discriminate, particularly } \\
\text { on the mental health unit, whether someone is impaired } \\
\text { in their reality testing and...they have no sense of } \\
\text { boundaries." (no. 05) }\end{array}$ & $\begin{array}{l}\text { Policies/guidelines } \\
\text { Staff training }\end{array}$ \\
\hline
\end{tabular}

*Themes are not mutually exclusive and multiple themes may apply to a single quote 
stated, "It's the lack of accountability, it's an umbrella, it goes over everything, so until that is taken care of, nothing will work on any level." (no. 01).

Several participants pointed out that VA culture and climate are reflections of larger societal culture. One summarized, "We're a microcosm of the world, so culture change here is culture change in the world." (no. 06). However, other participants expressed concern that VA tolerates harassment of women by men patients more than other healthcare organizations: "Even as residents.... rotating among multiple hospitals...we were like, "What is up with the patients at the VA that they think they can do this to us?"” (no. 18).

Some participants attributed VA's culture and climate around harassment to its association with military culture. They pointed to military conceptions of gender roles that carry over to VA: "The majority of our population is still male and, culturally, we are so used to Veterans being labeled as male that I think frequently we forget that female Veterans are eight to ten percent of our population now." (no. 17). In addition to its masculine norms, the military's emphasis on group cohesion and its permissiveness toward gender harassment may combine to enable patient-perpetrated harassment at VA: "[It is] important among Veterans...to continue to have some sense of bonding with a group of military other people. And unfortunately, historically, culturally in the military a great deal of that bonding...has been cemented by sexual harassment." (no. 08). Further supporting this statement, participants named areas where men patients congregate and socialize, such as lobbies and entryways, as "hotspots" for public harassment of women.

Participants reported a lack of formal policies and guidelines for handling patient-perpetrated harassment. One administrator stated, "I have to say that we do not have a formal policy on it and we should have [one]. And I look at various policies; it may address it in a small way, but we are not as aggressive and expansive as I'd like it to be." (no. 17). Of the minority of participants who named policies or procedures, some expressed ambiguity around their application to patientperpetrated harassment. For example, several participants identified VA's Disruptive Behavior Committee as a resource, but also noted that it is designed to address "egregious" behaviors and may not be an appropriate intervention for "lower level" harassment (nos. 16, 22, 23).

Finally, although administrators in this study communicated investment in addressing harassment, some participants identified lack of leadership support as a barrier. As one stated, "Some [staff], when they don't speak up, it's because they're just not sure that leadership will have their backs." (no. 08). Others indicated that leaders are simply uninformed about the scope of the issue: "Even though we know it on the bottom end, I think sometimes the top doesn't see everything." (no. 13).

Staff Factors. In addition to organizational factors, participants identified individual staff-level barriers to addressing patient-perpetrated harassment of women staff and patients. These included cognitive appraisals, or staff assessments and judgments around labeling and categorizing harassment. As one explained, "Employees may not recognize situations as harassment or they may not feel that they're prepared to address it. I think in the overt situations they would know what to do, but something that would be much more minimal or a conversation or a comment..." (no. 03). Even when staff did view behavior as harassment, they sometimes downplayed its impact or significance, as in this participant's account of her internal dialog following harassment by a male patient: "Give it a little bit of time and the shock value wears off and it's like, 'Oh, I guess it wasn't that bad, so maybe I'm not going to [file a report]."” (no. 02).

Other staff-level challenges involved fears of negatively affecting patient-staff dynamics. Participants struggled to find the middle ground between maintaining the therapeutic relationship and addressing patient-perpetrated harassment, both directed towards them and towards women patients. Some reported that the VA emphasis on customer service further complicated the issue. As one participant asked, "When I'm trying to give good customer service, how do I give the customer service and still correct negative behavior? How can I negotiate that role?" (no. 07). Another participant described concerns about navigating issues of power: "You're a patient and I'm a provider so there's this inherent power difference but you're making me feel like I can't say anything. So I think it's just awkward in that way, like is that misusing our power to let them know how inappropriate [their behavior] is?" (no. 15). Others feared provoking negative patient reactions or retaliation: "If you tell the Veteran this isn't appropriate, the Veteran may or may not just go to the Patient Advocate... and you're the one who gets in trouble for commenting." (no. 01).

Finally, participants noted that competing staff priorities and limited resources act as barriers to addressing patientperpetrated harassment. One participant explained, "Especially [for] the nurses - the LPNs, the RNs...to sit down and fill out that report, on top of all those other things that they're being asked to do, I'm not so sure they're going to make it a priority." (no. 02). A member of the Disruptive Behavior Committee (DBC) stated, "The DBC handles extreme cases of [patients] who are like threatening to kill people, for example. And if they were also to handle the much, much larger number of comments that are sexually harassing...it would take a lot more time. So logistically that could be challenging." (no. 08).

Patient Factors. In addition to organizational and staff factors, patient characteristics may present challenges to addressing patient-perpetrated harassment of women staff and patients. Participants explained that some patients lack awareness and do not realize that their behaviors may be construed as harassing. For example, older patients may not realize that norms around harassment have changed: "There are some 
[men] Veterans who may comment, especially to younger women, who probably wouldn't view their comments or their behavior as abhorrent. It was in the context of how they grew up and the culture of their time." (no. 20). Participants also explained that certain clinical diagnoses complicate assessments of patient intentionality or culpability regarding harassment. In describing an incident of harassment by a male patient with a psychiatric disorder, a female participant stated, “...there was little attention paid to the actual harassment and it was justified by the mental illness versus the behavior. So it was kind of like brushed under the rug." (no. 13).

\section{Recommendations for Addressing Harassment}

As indicated in Table 1, participant recommendations for addressing patient-perpetrated harassment of women staff and patients often targeted specific barriers. To change culture and climate, participants stressed that VA should formally communicate that addressing harassment is an institutional priority. Communications may take the form of posters, norms campaigns, or system-wide emails. Norms campaigns may target harassment directly or indirectly via perceptions about women Veterans or staff. "Harassment is a put down, it's a power thing...I think if there's imagery of women as far as in uniform and the roles that they play in and around VA medical centers...it would be a very positive thing." (no. 05). Leaders can communicate that harassment is a priority via public expressions of support: "Having our leadership say something about it in meetings and saying to staff, 'I will support you if you need to reply to a Veteran or another staff person by telling them whatever they just said to you is inappropriate or it makes you uncomfortable'...would be useful." (no. 15).

Participants emphasized the need for greater education and training around harassment. As one participant stated, "I think for me, for this harassment thing, it's education and awareness - employee education, Veteran education..." (no. 21). Participants suggested that staff training should focus on teaching staff to recognize sexual and gender harassment and "respond to comments that are inappropriate, especially in the context of a clinical visit where you can't simply walk away because you have a provider-patient relationship that you need to maintain." (no. 20). In addition to responding to harassment directed at them, staff should be trained to intervene in cases of public harassment directed at patients, as commensurate with their roles: "Have some staff go out front and see what's going on and address it, and address it in front of other people." (no. 12). Prior to staff training, VA should develop policies around patient-perpetrated harassment grounded in transparency and accountability: "Where do [staff] report? What do they report? Is it going to be followed up?" (no. 09).

Participants suggested that patient education about harassment may take the form of sensitivity training during new patient orientation or workshops to increase patient awareness "that [women] have a story of where they've come from and to take that into account with interactions." (no. 03). Some participants stated that training patients in bystander intervention might be a good fit with VA and military culture: "[Men patients are] much more open to suggestions by a Veteran and I think it holds more weight because of that brethren.” (no. 13). They noted that bystander intervention is particularly useful in cases of public harassment where the perpetrator is unknown to the target and reporting may be difficult. However, others cautioned that bystander intervention may trigger violence among patients or that patients should not be held responsible for intervening in harassment, signaling a need for further investigation of the fit between bystander intervention and the VA context.

\section{DISCUSSION}

We explored challenges and recommendations for addressing patient-perpetrated sexual and gender harassment of women staff and patients at VA healthcare facilities. Challenges spanned organizational levels and involved a range of stakeholder groups. Consistent with this systemic conceptualization, recommendations targeted leaders, staff, and patients, and encompassed both primary prevention and secondary intervention strategies.

At the organizational level, a significant challenge is a climate that communicates tolerance for harassment, aligning with other research demonstrating the critical roles of culture and climate in creating organizational change. ${ }^{25,39,40} \mathrm{~A}$ lack of formal policies and guidelines around patient-perpetrated harassment, similar to the policy gaps found in other healthcare contexts, enables this climate. $^{19,} 22$ Taken together, these findings indicate an urgent need for clear, well-disseminated, action-oriented policies addressing how to report and/or intervene around patient-perpetrated harassment. ${ }^{41}$ As study participants noted, leadership must publicly uphold and enforce these policies in order for them to be effective. ${ }^{29,41}$

After clear policies and guidelines are developed, staff-level interventions should focus on reducing the ambiguity around labeling and addressing harassment described by participants. In line with recommendations based on other studies, staff should receive training related to definitions of harassment, patient and employee codes of conduct, scripts and algorithms for responding to patients who harass, and procedures for reporting harassment. ${ }^{20-22,41}$ Given the complexities of addressing harassment in the context of the patient-provider relationship, training modalities should emphasize behavior modeling, practice and feedback, and examples grounded in clinical reality. ${ }^{42}$

Patient-level challenges included characteristics such as older age and cognitive or physical impairment that influence intentionality behind harassment. Together with findings from other research, these results suggest the importance of striking a balance between empathizing with patients who harass and setting appropriate boundaries around their behavior. ${ }^{28}$ However, further investigation is needed to determine how to tailor educational interventions to different patient 
populations. Beyond basic education, clinics or hospitals with identified harassment "hotspots" may explore training staff and select patients in bystander intervention, one of the most promising strategies for addressing public harassment. ${ }^{43}$ Potential bystander intervention strategies involve redirecting the harasser, interrupting the situation, providing support to the target, and reporting the harasser. ${ }^{44,} 45$

Challenges to addressing patient-perpetrated harassment were interrelated across organizational levels. For example, some participants indicated that patients should not be held responsible for intervening if they experience or witness harassment, particularly if staff and leaders do not hold harassers accountable. Similarly, some staff did not feel comfortable addressing harassment in the absence of supportive policies and leadership. These findings suggest that interventions should take a multilevel approach, starting with the top of the organization, in order to communicate that addressing harassment is everyone's responsibility.

This study's limitations should be kept in mind when interpreting results. First, the VA setting offered unique opportunities for understanding patient-perpetrated harassment in the largest healthcare system in the USA but may limit applicability of findings to non-VA settings. We are not aware of any studies comparing harassment in VA and non-VA healthcare facilities, but our findings suggest that VA settings may have an increased tolerance for harassment of women due to the influence of military gender norms. Second, interviews took place before VA's campaign against harassment and the popularization of the \#MeToo and \#TimesUp movements so stakeholder perceptions may have since evolved. Third, interview questions did not distinguish between challenges related to patient harassment of staff versus patient harassment of other patients, and some findings may be more relevant to one form of harassment or the other. Finally, this manuscript focused exclusively on employee perceptions, although research examining VA patient perspectives on harassment is ongoing. ${ }^{30}$

Our findings suggest multiple directions for future work. In 2017, VA launched an "End Harassment" norms campaign, which included placement of signs and posters targeting climate around harassment. ${ }^{46}$ Alongside rollout of the campaign, VA began annual data collection to track prevalence of harassment of women Veterans. More recently, VA executive leadership announced a "Stand Up to Stop Harassment Now" initiative that included initial funding to facilitate bystander intervention training. At campaign launch, facility directors made public commitments to addressing harassment of women and supporting incident reporting (Richard Stone, memo to Veterans Health Administration employees, October 23, 2019). Further steps include collaboration between VA leadership and researchers to explore effective harassment reduction strategies and programs. To our knowledge, this is one of few recent studies focusing on challenges to addressing patient-perpetrated harassment in healthcare settings, and additional research is needed to corroborate and expand upon findings. Future research can compare organizational climate related to harassment in VA and non-VA settings and assess challenges to addressing other forms of harassment (e.g., harassment targeting men and LGBTQ individuals).

\section{CONCLUSION}

Challenges to addressing patient-perpetrated harassment of women in healthcare are longstanding and rooted across organizational levels. Change requires multifaceted, systemic interventions that shift organizational climate and support providers in responding to harassment. As one stakeholder in this study stated, "It didn't get screwed up in a day; it takes more than a day to fix it."

Acknowledgments: We are grateful to the participants for sharing their time and expertise. We wish to thank Lisa Tarr for scheduling the interviews.

Corresponding Author: Karissa M. Fenwick, PhD, MSW, LCSW; Center for the Study of Healthcare Innovation, Implementation and Policy (CSHIIP), VA Greater Los Angeles Healthcare System, Health Services Research and Development (HSR\&D), Los Angeles, CA, USA (e-mail: karissa.fenwick@va.gov).

Funding This work was financially supported by Women's Health Services in the Office of Patient Care Services, Veterans Health Administration, United States Department of Veterans Affairs (XVA 65-092). Contacts with participating sites were facilitated by the VA Women's Health Practice-Based Research Network (PBRN) (SDR 10-112).

Dr. Fenwick was supported by the VA Office of Academic Affiliations through the Health Services Research fellowship program (TPH 65000-15). Dr. Dyer and Dr. Klap's efforts were partially funded under a VA HSR\&D pilot grant (PPO 18-112). Dr. Yano was supported by a VA HSR\&D Senior Research Career Scientist Award (RCS 05-195).

\section{Compliance with Ethical Standards:}

VA Office of Women's Health designated this project as a quality improvement/evaluation activity rather than research. However, we obtained participant consent for audio recording and upheld standards for participant privacy and data security.

Conflict of Interest: The authors declare that they do not have a conflict of interest.

Disclaimer: Views expressed in this article are our own and do not necessarily represent the position or policy of the Department of Veterans Affairs or the US government.

\section{REFERENCES}

1. Fitzgerald LF, Gelfand MJ, Drasgow F. Measuring sexual harassment: theoretical and psychometric advances. Basic Appl Soc Psych. 1995;17(4):425-45. https://doi.org/10.1006/jvbe.1995.1033

2. Vargas EA, Brassel ST, Cortina LM, Settles IH, Johnson TRB, Jagsi R. \#MedToo: A large-scale examination of the incidence and impact of sexual harassment of physicians and other faculty at an academic medical center. J Womens Health (Larchmt). 2020;29(1):13-20. https://doi.org/ 10.1089/jwh.2019.7766

3. Boissonnault JS, Cambier Z, Hetzel SJ, Plack MM. Prevalence and risk of inappropriate sexual behavior of patients toward physical therapist clinicians and students in the United States. Phys Ther. 2017;97(11): 1084-93. https://doi.org/10.1093/ptj/pzx086

4. Fnais N, Soobiah C, Chen MH, et al. Harassment and discrimination in medical training: a systematic review and meta-analysis. Acad Med. 2014;89(5):817-27. https://doi.org/10.1097/ACM.0000000000000200 
5. Jenner S, Djermester P, Prugl J, Kurmeyer C, Oertelt-Prigione S. Prevalence of sexual harassment in academic medicine. JAMA Intern Med. 2019;179(1):108-11. https://doi.org/10.1001/jamainternmed.2018.4859

6. Moylan CA, Wood L. Sexual harassment in social work field placements.Affilia. 2016;31(4):405-17. https://doi.org/10.1177/ 0886109916644643

7. Spector PE, Zhou ZE, Che XX. Nurse exposure to physical and nonphysical violence, bullying, and sexual harassment: a quantitative review. Int J Nurs Stud. 2014;51(1):72-84. https://doi.org/10.1016/j. ijnurstu.2013.01.010

8. Friborg MK, Hansen JV, Aldrich PT, et al. Workplace sexual harassment and depressive symptoms: a cross-sectional multilevel analysis comparing harassment from clients or customers to harassment from other employees amongst 7603 Danish employees from 1041 organizations. BMC Public Health. 2017;17(1):675. https://doi.org/10.1186/s12889-017-4669-x

9. National Academies of Sciences, Engineering, and Medicine (NASEM). Sexual harassment of women: climate, culture, and consequences in academic sciences, engineering, and medicine. Washington, D.C.: National Academies Press; 2018. https://doi.org/10.17226/24994

10. Purcell N, Shovein E, Hebenstreit C, Drexler M. Violence in a U.S. Veterans Affairs healthcare system: worker perspectives on prevalence, causes, and contributors. Policy Pract Health Saf. 2017;15(1):38-56. https://doi.org/10.1080/14773996.2016.1266439

11. Kearl $\mathbf{H}$. The facts behind the \#MeToo movement: a national study on sexual harassment and assault. Reston, VA: Stop Street Harassment 2018. http://www.stopstreetharassment.org/wp-content/uploads/ 2018/01/Full-Report-2018-National-Study-on-Sexual-Harassment-andAssault.pdf. Accessed December 20, 2019.

12. Klap R, Darling JE, Hamilton AB, et al. Prevalence of stranger harassment of women Veterans at Veterans Affairs Medical Centers and impacts on delayed and missed care. Womens Health Issues. 2019;29(2): 107-15. https://doi.org/10.1016/j.whi.2018.12.002

13. Fairchild K, Rudman LA. Everyday stranger harassment and women's objectification. Soc Justice Res. 2008;21(3):338-57. https://doi.org/10. 1007/s11211-008-0073-0

14. Logan LS. Street harassment: current and promising avenues for researchers and activists. Sociol Compass. 2015;9(3):196-211. https:// doi.org/10.1111/soc4.12248

15. Choo EK, Byington CL, Johnson NL, Jagsi R. From \#MeToo to \#TimesUp in health care: can a culture of accountability end inequity and harassment? Lancet. 2019;393(10171):499-502. https://doi.org/10. 1016/S0140-6736(19)30251-X

16. Dzau VJ, Johnson PA. Ending sexual harassment in academic medicine. N Engl J Med. 2018;379(17):1589-91. https://doi.org/10.1056/ NEJMp 1809846

17. Fairchild AL, Holyfield LJ, Byington CL. National Academies of Sciences, Engineering, and Medicine report on sexual harassment: making the case for fundamental institutional change. JAMA. 2018;320(9):873-4. https://doi.org/10.1001/jama.2018.10840

18. Killeen OJ, Bridges L. Solving the silence. JAMA. 2018;320(19):1979-80. https://doi.org/10.1001/jama.2018.15686

19. Viglianti EM, Oliverio AL, Cascino TM, Meeks LM. The policy gap: a survey of patient-perpetrated sexual harassment policies for residents and fellows in prominent U. S. hospitals. J Gen Intern Med. 2019;34(11):2326-8. https://doi.org/10.1007/s11606-019-05229-7

20. Viglianti EM, Oliverio AL, Meeks LM. Sexual harassment and abuse: when the patient is the perpetrator. Lancet. 2018;392(10145):368-70 https://doi.org/10.1016/S0140-6736(18)31502-2

21. Farkas AH, Scholcoff $\mathbf{C}$, Machen $\mathbf{J L}$, et al. The experience of male physicians with sexual and gender-based harassment: a qualitative study. J Gen Intern Med. 2020;35(8):2383-8. https://doi.org/10.1007/ s11606-020-05695-4

22. Scholcoff C, Farkas A, Machen JL, et al. Sexual harassment of female providers by patients: a qualitative study. J Gen Intern Med. 2020. https://doi.org/10.1007/s11606-020-06018-3

23. Cortina LM, Jagsi R. What can medicine learn from social science studies of sexual harassment? Ann Intern Med. 2018;169(10):716-7. https://doi.org/10.7326/M18-2047

24. Kabat-Farr D, Cortina LM. Sex-based harassment in employment: new insights into gender and context. Law Hum Behav. 2014;38(1):58-72. https://doi.org/10.1037/lhb0000045

25. Willness CR, Steel P, Lee $\mathbf{K}$. A meta-analysis of the antecedents and consequences of workplace sexual harassment. Pers Psychol. 2007;60(1):127-62. https://doi.org/10.1111/j.1744-6570.2007.00067.x
26. Timmerman G, Bajema C. The impact of organizational culture on perceptions and experiences of sexual harassment. J Vocat Behav. 2000;57(2): 188-205. https://doi.org/10.1006/jvbe.1999.1741

27. Baker L. Sexual harassment by patients forces doctors to alter their practice. BMJ. 2014;348:g118. :https://doi.org/10.1136/bmj. g118

28. Nielsen MBD, Kjaer S, Aldrich PT, et al. Sexual harassment in care work - dilemmas and consequences: a qualitative investigation. Int $\mathrm{J}$ Nurs Stud. 2017;70:122-30. :https://doi.org/10.1016/j.ijnurstu.2017. 02.018

29. Buchanan NT, Settles IH, Hall AT, O'Connor RC. A review of organizational strategies for reducing sexual harassment: insights from the U. S. military. J Soc Issues. 2014;70(4):687-702. https://doi.org/10.1111/ josi. 12086

30. Dyer KE, Potter SJ, Hamilton AB, et al. Gender differences in Veterans' perceptions of harassment on Veterans Health Administration grounds. Womens Health Issues. 2019;29 Suppl 1:S83-S93. https://doi.org/10. 1016/j.whi.2019.04.016

31. Frayne SM, Phibbs C, Saechao F, et al. Sourcebook: women Veterans in the Veterans Health Administration. Volume 4: longitudinal trends in sociodemographics, utilization, health profile, and geographic distribution. Washington, D.C.: Department of Veterans Affairs; 2018.

32. Barth SK, Kimerling RE, Pavao J, et al. Military sexual trauma among recent Veterans: correlates of sexual assault and sexual harassment. Am J Prev Med. 2016;50(1):77-86. https://doi.org/10.1016/j.amepre.2015.06.012

33. Wilson LC. The prevalence of military sexual trauma: a meta-analysis. Trauma Violence Abuse. 2018;19(5):584-97. https://doi.org/10.1177/ 1524838016683459

34. Miles-McLean H, Liss M, Erchull MJ, et al. Stop looking at me!: interpersonal sexual objectification as a source of insidious trauma. Psychol Women Q. 2015;39(3):363-74. https://doi.org/10.1177/ 0361684314561018

35. Hayes PM. Improving health of Veterans through research collaborations. J Gen Intern Med. 2013;28 Suppl 2:S495-7. https://doi.org/10.1007/ s11606-013-2471-8

36. Frayne SM, Carney D, Bastien L, et al. The VA Women's Health PracticeBased Research Network: amplifying women Veterans' voices in VA research. J Gen Intern Med. 2013;28 Suppl 2:S504-9. https://doi.org/ $10.1007 / \mathrm{s} 11606-013-2476-3$

37. Miles MB, Huberman AM, Saldaña J. Qualitative data analysis: a methods sourcebook. Third edition. ed. Thousand Oaks, CA: Sage Publications, Inc.; 2014

38. Charmaz K. Constructing grounded theory. 2nd ed. Thousand Oaks, CA: Sage Publications, Inc; 2014

39. Schneider B, Ehrhart MG, Macey WH. Organizational climate and culture. Annu Rev Psychol. 2013;64:361-88. https://doi.org/10.1146/ annurev-psych-113011-143809

40. Fitzgerald LF, Drasgow F, Hulin CL, Gelfand MJ, Magley VJ. Antecedents and consequences of sexual harassment in organizations: a test of an integrated model. J Appl Psychol. 1997;82(4):578-89. https://doi.org/10.1037/0021-9010.82.4.578

41. Jenner SC, Djermester P, Oertelt-Prigione S. Prevention strategies for sexual harassment in academic medicine: a qualitative study. J Interpers Violence. 2020. https://doi.org/10.1177/0886260520903130

42. Medeiros K, Griffith J. Ustoo: How I-O psychologists can extend the conversation on sexual harassment and sexual assault through workplace training. Int Perspect Psychol. 2019;12(1):1-19. https://doi.org/10. 1017/iop.2018.155

43. Coker AL, Bush HM, Cook-Craig PG, et al. RCT testing bystander effectiveness to reduce violence. Am J Prev Med. 2017;52(5):566-78. https://doi.org/10.1016/j.amepre.2017.01.020

44. Bowes-Sperry L, O'Leary-Kelly AM. To act or not to act: the dilemma faced by sexual harassment observers. Academy Manage Rev. 2005;30(2):288-306. https://doi.org/10.5465/amr.2005.16387886

45. Lee SY, Hanson MD, Cheung HK. Incorporating bystander intervention into sexual harassment training. Ind Organ Psychol. 2019;12(1):52-7. https://doi.org/10.1017/iop.2019.8

46. Hayes PM. VA: It's our responsibility to end harassment. Vantage point: official blog of the U S Department of Veterans Affairs. https: / www.blogs. va.gov/VAntage/64559/va-our-responsibility-end-harassment/. Published August 15, 2019. Accessed February 10, 2020.

Publisher's Note: Springer Nature remains neutral with regard to jurisdictional claims in published maps and institutional affiliations. 